\title{
Encouraging Family Business Members to Go the Extra Mile
}

\author{
Kimberly Eddleston (Northeastern University) \\ Franz Kellermanns (UNC - Charlotte \& WHU) \\ Roland Kidwell (Florida Atlantic University)
}

KEYWORDS: Management, Family Business, human resources.

Family firms typically emphasize one of two management approaches: stewardship, which stresses participation, adaptability and family harmony; and agency, which emphasizes discipline, management and control. Researchers from Northeastern University, University of North Carolina-Charlotte and Florida Atlantic University set out to discover which type of approach gets better results, as measured by the number of times employees took the initiative to do something outside the scope of their jobs. They found that a hybrid of both approaches -- the collaboration and adaptability used in the stewardship approach and the monitoring and feedback used in the agency approach -- encouraged more employees to go the extra mile. This video summarizes their findings.

To access the full research paper, click here (https://onlinelibrary.wiley.com/doi/abs/10.1002/hr m.21825) . 